\title{
Intoxicação por chumbo em crianças e o discurso da imprensa
}

\section{Lead poisoning in children and media discourse analysis}

Nilce Emy Tomita 1

Niura Ap a recida de Mo ura Ribei ro Padula 2 GEPICCB 3

\footnotetext{
${ }^{1}$ Departamento de Odon topediatria, Ortodon tia e Sa ú deColetiva da Faculdade de Odontologia de Bauru da Un iversidade de São Paulo. Al. Octávio Pinhei ro Brisolla 9-75, 17012-101, Bauru SP.

netomita@usp.br

2 Departamento de Neu rologia e Psiquiatria da Faculd ade de Medicina de Bo tucatuda Un iversidade Estadual Júlio de Mesquita Filho.

3 Grupo de Estu do

e Pes quisa da In toxicação por Chu mbo em Crianças de Bauru.
}

Abstract The finding and interdiction of a battery factory with high lead emission got massive media coverage in the city of Bauru (SP), in 2002, given the relevance of this issue to public health. Aiming at evaluating the publications in the press related to lead environmental contamination in a residential area, its repercussion on infantile health and the initiatives of government to face this subject, the present study has been delineat$e d$. The analysis of the press discourse is acco mplished by the reading of news published in the year of 2002, using tools of qualitative analysis. Starting from the approach of the press on this sequence of events, this reflection represents a contribution to the elaboration of educational programs that focus on the care of the environment and its impact on public health.

Key words Lead poisoning, Environment, Children, Printed media, Intersectorial action
Resumo Houve ampla div ulgação na mídia sobre a descoberta e interdição de uma fábrica de baterias com elevada emissão de chumbo, no município de Bauru (SP), em 2002, dada a relevância do assunto pa ra a saúde pública. O objetivo deste estudo é avaliar as pu blicações na imprensa relativas à contaminação ambi ental por chumbo em uma área residencial, sua repercussão sobre a saúde infantil e as iniciativas do poder público para enfrentamen to desta questão. A análise do discurso da imprensa escrita é realizada mediante a leitura de notícias publicadas no ano de 2002, utilizando ferramentas de análise qualitativa. A partir da abordagem da imprensa sob re esta sucessão de acontecimentos, esta refl exão constitui uma contribuição à elaboração de programas educativos que têm como foco os cuidados com o meio ambiente e as suas repercussões sobre a saúde da população.

Palavras-chave Chumbo, Meio ambiente, Crianças, Mídia impressa, Ação intersetorial 


\section{Introdução}

Nas sociedades modernas, os meios de comunicação ocupam um lu gar privilegi ado de produção e reprodução do real, com forte influência cultural. O papel da mídia impressa se realiza em dois planos: um que procura narrar as notícias do dia, procu rando cumprir sua função informativa; outro, no qual se configurae expressa um sistema de valores, associado ao lugar do jornal como sujeito da enunciação (Njaine \& Minayo, 2002).

Lèfevre (1996) define o fato como um acontecimento, algo que ocorre ou acon tece como uma inundação, uma partida de futebol, um incêndio e que é trabalhado pela mídia como instaurador de uma gramática de produção de fatos. Mas a des-co n s trução ou des-montagem do discurso e da retórica jornalística ou midiática permite mostrar que a geração espontânea do fato é um efei to de discurso e (...) que sempre subjaz, implícita, uma con cepçãa do fato, uma contextualização, uma gênese, uma teoria e uma explicação, a serem resgatadas.

Essa con textualização pode ser vista nas notícias re sgatadas de três jornais ao de screverem uma sucessão de fatos ocorridos em Ba u ru (SP), após a interdição de uma indústria de baterias, em que se detectou emissão de chumbo acima dos padrões acei tá veis (Quitério et al., 2003).

Com relação ao jornal, Can clini (2002) observa estar diante de um meio que oferece mais elementos discursivos que ou tros pa ra refletir sobre a cidade e elaborar a condição de cidadão, mas que não contribui para expandir a visão sobre a cidade em uma proporção comparável ao crescimento de seu território e sua complexidade. Assim, mais do que estabelecer novos lugares de pertencimen to e de iden tificação de raizes, o importante pa ra as mídias é oferecer certa intensidade de experiências.

\section{Breve históri co do fato}

Em ja n ei rode 2002, n o tificação da Com p anhia de Tecnologia de Saneamento Ambiental (Cetesb) à Secretaria Municipal de Saúde de Ba uru informava sobre teores de chu mbo oriundo de resíduos industriais (São Paulo, 2002) como fonte de contaminação e conseqüentes agravos à saúde de parte de sua população (Cen ters for Disease Con trol, 2002; Paolielo et al., 1997, Morei ra \& Moreira, 2004).

A partir da localização de uma fábrica de acumuladores (baterias), instalada desde 1958 em área periférica domunicípio, dej etos com sal de óxido de chumbo e sulfatode chumbo presentes na poei ra (pluma) e a deposição de chu mbo metálicono solo foram detect ados (Instituto Am bi ental Vidágua, 2002; São Paulo, 2002).

Mediante a existência de 314 crianças com taxas de plu mbemia su periores àqu elas aceitá-

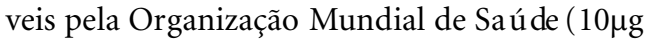
$\mathrm{Pb} / \mathrm{dl}$ sangue), foram desen cade adas ações em ergenciais, visandoreduzir ris cos de re-contaminação, que incluíram a raspagem de camada superficial das vias públicas, resultando em $1.392 \mathrm{~m}^{3}$ de terra com material tóxico, que permanece depositada nas dependências da fábrica. Foi promovida a aspiração de poei ra do interi or de 164 residências, utilizandoequipamento indu strial, bem como a lavagem eved a mento das caixas d'água (Tomita \& GEPICCB, 2003).

Este fato inédito na história do município suscitou, por parte da mídia, uma série de matérias de cunho jomalístico sobre a contaminação por chumbo em Bauru. Aliados à relevância do assun to para a saúde pública, alguns aspectos sociais permearam a abordagem da impren sa, $s$ obretu do aqueles rel acion ados às conseqüências da interdição da empresa.

A cronologia dos fatos pode ser acomp anhada pelo material impresso, recuperado a partir de recortes de jornal, partin do do princípio que a imprensa escrita tem importante papel no "processo de acumulação cultural e docum entação da história de uma socied ade" (Moreira et al. , 2002).

O presen te estudo tem por objetivo analisar as publicações da imprensa rela tivas à contaminação ambi ental por chumbo, sua repercussão sobre a saúde infantil e as iniciativas do poder públ i co para o enfrentamento des te problema, tendo como pressuposto teórico que o noticiário pode exercer um papel importante no controle social, dando voz aos diferentes pers onagens envo lvidos na história.

\section{Método}

A pesquisa que serve de base a este trabalho tem como matéria-prima textos publicados em dois jornais de circulação nacional (Folha de S. Paulo e O Estado de S. Paulo) e um jornal de circulação loco-regi onal (Jornal da Cidade). Foram sel ecion ados artigos que faziam menção à contaminação por chumbo no município de Bauru (SP), no período de feverei ro a dezembro de 2002. 
A notificação da Cetesb que desencadeou a su cessão de fatos ocorreu em jan ei ro de $2002 \mathrm{e}$ as primeiras matérias na imprensa foram publicadas a partir de abril daquele ano. Foram recuperadas 66 matérias publicadas no ano de 2002, que foram inicialmen te dispostas em ordem cronológica. A nu meração nos quadros 1, 2 e 3 respeita esta ordem.

No trabalho empírico, a leitura do material im presso propiciou a criação de três categorias explicativas: o que acon teceu (e suas repercussões sociais), o que foi descoberto (diagnósti co médicoe epidemiológico) e o que foi fei to (intervenções ambientais e dínicas). Os extratos de discursos são citados em itálico no pres en te trabalho e sua nu m eração se refere ao título da matéria dispo s to nos quad ros.

A tridimensionalidade dos efeitos do discurso, en tendida como tex to, in teração e prática social (Njaine \& Minayo, 2002) propicia um exercício de enten dimen to da sucessão de fato $s$ ocorri dos após a detecção de ste probl ema ambiental, permitindo uma análise de natureza qualitativa (Min ayo, 1993).

\section{Resultados e discussão}

\section{O que acon teceu}

Matérias jomalísticas que foram dassificadas na categoria explicativa o que aconteceu lançaram luz sobre uma seqüência de fatos orden ados historicamente, revel an do à sociedade um aciden te ambiental, as reações dos moradores e algumas repercussões sociais, além da reação da empresa.

Caso Ajax está na lista do Greenpeace. Bauru é uma das 17 localidades do Brasil que, segundo en tidade ambientalista, sof re com contaminação indu strial 25 (Quad ro 1).

As notícias desta categoria foram com pon do um mosaico, em que a perplexid ade da população se somou à inquietação dos moradores da área mais diretamen te atingida. Moradores das chácaras vizinhas do setor metalúrgico da Acumuladores Ajax aguardam o resultado do laudo do solo apreensivos. 1

Algumas repercussões do fato gerador da notícia denotam um aspecto econômico, uma vez que, desde a orientação dada pela Secretaria Municipal de Saúde, pa ra suspender o consumo de ovos de aves criadas nas propriedades rurais, lei te das vacas (...) e de algumas verdu ras, a vida dos mora do resmud ou: estão comprando alimentos que até então produziam. ${ }^{1}$

Além da incidência de chumbo (...) e da precariedade de infra-estrutu ra urbana, como falta de iluminação, asfalto, galeria pa ra águas pluviais e postos de saúde próximos, os moradores das áreas próximas à fábrica de baterias Ajax (...) ago ra têm mais um motivo para reclamar: seus imóveis perderam valor depois do conhecimento dos altos índices de chumbo na área. ${ }^{49} \mathrm{Es}$ sa população vulnerável, como outras que se viram em situação semelhante na história recente do Brasil, como as residen tes em San to Amaro da Pu rificação (BA) e Adrianópolis (PR),

Quadro 1

Títulos de matérias jornalísticas sobre a contaminação por chumbo: $\mathrm{O}$ que acon teceu (abril a de zem bro de 2002).

\begin{tabular}{lll}
\hline & Jornais/matérias & Data \\
\hline 1 & JC/Chumbo altera a vida de moradores & $25 / 04 / 2002$ \\
2 & FSP/Descontrole cria “bombas- relógio" em SP & $28 / 04 / 2002$ \\
16 & JC/Chu mbo ou chumbada & $16 / 05 / 2002$ \\
42 & JC/Comissão que sti ona a demora para os laudos & $14 / 08 / 2002$ \\
43 & JC/Ajax vai acatar medidas da DIR-10 & $14 / 08 / 2002$ \\
45 & JC/Moradores ainda utilizam córrego & $16 / 08 / 2002$ \\
46 & JC/Fábrica Ajax considera a interdição precipitada & $16 / 08 / 2002$ \\
49 & JC/Área contaminada está desvalorizada & $21 / 08 / 2002$ \\
50 & JC/Crianças con ti nuam brincandona terra & $21 / 08 / 2002$ \\
53 & JC/Ajax pode levar fábrica para Agudos & $5 / 09 / 2002$ \\
57 & JC/Terramérica: com o chu mbo não se brinca & $9 / 10 / 2002$ \\
59 & JC/Vereador qu es ti ona moro sid ade em relação à execução dos trabalhos & $14 / 10 / 2002$ \\
65 & JC/Chuva atrapalha descontaminação & $5 / 11 / 2002$ \\
66 & JC/Moradores impedem descontaminação & $15 / 11 / 2002$ \\
\hline
\end{tabular}


percebe-se diante de perdas e as relata por meio do noticiário.

Segundo Porto (2002), a ori gem conceitual de vuln erabilid ade remonta à concepção ecossistêmica de resiliência (capacidade de um sistema recuperar-se fren te a perturbações) e aos estudos sob repopulações excluídas em países do Terceiro Mundo, que de certo modo vivem uma situação de "desastre cotidiano" frente às precárias condições de vida e sob revivência. O tema da vuln erabilidade tem especial relevância ao designar tan to os proces sos geradores quanto as cara cterísticas das populações e regiões quepo ssu em maiores dificuldades de absorver os impa ctos de eventos de risco.

Diantedestes fatos gerados pela de s coberta da exposição a um agente tóxico e dos seus efeitos sobre este grupo populacional, possibilidades de enfrentamen to vão sen do buscadas. $\mathrm{Na}$ seqüência dos acon tecimentos, foi noticiada a implantação, em agosto de 2002, de uma Comissão de Saturnismo, in tegrada pelo Sind ic ato dos Metalúrgicos de Bauru, Secretaria Municipal do Meio Ambiente, Secretaria Municipal do Desenvolvimen to Econômico, Institu to Ambiental Vidágua, Departamento de Saúde Coletiva, Delegacia Regional de Saúde (DIR 10), Centro das Indústrias do Estado de São Paulo (Ciesp), Mnistério do Trabalho, Em presa Ajax, Associação de Morado res Tangarás e Câmara Municipal de Bauru. ${ }^{2} \mathrm{~A}$ imprensa participa à sociedade uma mobilização inters etorial para melhor compreen der a questão ambi en tal.

Após a interdição da em presa, foi noticiado que, apesar de acreditar na possibilidade de que a liberação de chumbo (...) tenha sido provocada por uma fábrica dandestina, a empresa mostrase disposta a seguir as recomendações feitas pelos órgãos de saúde.43 Observa-se que o papel da imprensa, como veículo de ex pressão plu ral de d iversos segmen tos sociais, não pers egue o objetivo de ju l gar ou punir, mas propicia aos diferentes pers on a gens envo lvidos no processo um canal de expressão.

Os jornais, enquanto dispositivos do campo das mídias, estabelecem uma tensão de forças e de relações simbólicas com os demais campos de saberes e de poderes, aspectos que são ilustrados pelo conjunto de transações realizadas mediante o trabalho simbólico propriamente dito e que se caracteriza pela intervenção daquele no processo de rotinas e de construção dos acontecimentos (Morei ra et al., 2002).

Numa espécie de encruzilhada entre engajamen to e imparcialidade, nem sempre o dis- curso do noticiário é neutro ou isento, $\mathrm{n}$ em se pres supõe ju sto. A leitura das notícias mostra uma alternância de tons na abordagem dos fatos que vão se su ceden do.

Se, em alguns momentos, a imprensa escrit a parece exercer uma espécie de parceria com os s erviços públi cos no sentido da divulgação da in formação, por outro, também amplifica a voz de uma população que expressa inquietações. Maria alega que a maioria das informações que ela obtém sobre a contaminação da terra e os perigos que corre (...) são dos veículos de comunicação. Ela diz que a equipe da saúde esteve lá e avisou o que estava acontecendo, mas já faz tempo. 45

A imprensa também cobra providências, na voz de um morador, que refere que a empresa deveria arcar com os custo s. 50

Por sua vez, diante da interdição do setor metalúrgi co, a em presa divulga estar em fase de co nversações que podem resultar na transferência de pelo menos uma parte da fábrica de baterias para Agudos (município distante cerca de 10 km de Bauru)... Em Bauru desde 1958, a empresa é gerado ra de aproximadamente $1.000 \mathrm{em}$ pregos na cidade, porém esta matéria ressalva que um detalhe que talvez possa interferir nessa possivel transferência é o fato da Ajax vir a ter que providenciar (...) a repa ração de supostos danos ambi entais causados em Ba uru. 53

As vozes do poder público são expressas por meio das falas de um vereador, considerando que além da lentidão do trabalho, percebemos que as col a bo rações por pa rte da em presa são mínimas. Ela deveria assumir todo o ônus da descontaminação. A administração municipal não pode se responsabilizar por estes custos sozinha. Compartilha da mesma opinião o "promotor do meio ambien te", pa ra quem a posição da empresa (escassa colaboração no processo de descontaminação) seria uma estratégia jurídica... Por sua vez, a "secretária municipal de saúde" confirmou que a empresa tem respondido com presteza às reivindicações feitas. 59

Morei ra et al. (2002) observam que a mídia procura estabelecer uma relação que contemple os interesses de diferen tes públicos, visando ser significativo como formador de opinião pública, veiculando noticias informativas, relevantes e bem fundamentadas aos seus leitores. A relação da imprensa com a cidade é, por outro lado, entendida pela observação que $a$ desordenada explosão rumo às periferias (...) faz com que os habit a n tespercam o sen tido dos limites de "seu" território (que) é equilibrada com os relatos dos meios de comunicação sob re o que acon- 
tece nos luga res mais distantes dentro da cidade (Canclini, 2002). Assim, a con strução sociodemográfica de uma cidade e a compreensão do que nela acon tece se faz com import a n te apoio do diálogo mediado pelos jornais.

\section{O que foi descoberto}

Ao abordar o que foi de scoberto, o papel da imprensa como tradutor de diagnósti cos médico-dínicos, epidemiológicos e ambi entais mostra uma atuação de "mediação" entre os diferen tes setores da socied ade. O exces so de chumbo no sangue pode provocar anemia crônica, alterações no crescimento e problemas renais e neurológicos, como ret a rdo mental,3 (...) uma doença denominada satu rnismo (...) e até a morte. 34

Embora estas informações sejam corretas sob o pon to de vista técnico (Rojas et al., 2003; Moreira \& Moreira, 2004), a natu reza complexa, subjetiva e con tex tual da relação en tre saúde-doença-cuidado, descrita em outros estudos que envo lvem a análise de percepção de moradores da periferia urbana sobre as questões a mbi entais (Rego et al., 2002), não é descrita na imprensa (Quad ro 2).

Atuando como porta-voz dispos to a compartilhar os diagnósti cos proven i en tes das análises laboratoriais, as chamadas na imprensa vão enfileira n do números em ordem cres cente: Em Bauru, já são 88 crianças intoxicadas. ${ }^{3}$ Alta dosagem de chumbo já atinge 124 crianças. ${ }^{4}$ Já são 162 com alta dosagem de chumbo. 17 Contaminados por chumbo já são 186.21 Alta dosagen de chumbo já atinge 213.23 De sde março (...) já são 263 pessoas - 262 crianças e uma gestante - com mais de dez microgramas de chumbo por decilitro de sangue. 26 O número de crianças (...) subiu pa ra 275 com a chegada de mais um lote de resultados de exames. ${ }^{34}$ Uma das 295 crianças que estão contaminadas por chumbo em Bauru morreu no sábado, devido a uma pneumonia. 56 Acima desta referência (10 microgramas por decilitro de sangue) ficaram 307 menores. 60

A delimitação de um supos to nexo causal entre a emissão de poluentes e a saúde da população infantil é refor çada, no discurso da imprensa, por avaliações descritivas (traduzidas pelos níveis de plumbemia), reduzindo a compreensão do processo de adoecimen to a uma questão numérica. Com relação à possível associação entre doença e fato res de risco ambientais (...) não se trata apenas de uma ação externa de um elemen to ambi ental agress ivo, nem da reação de um hosped ei ro su sceptivel, senão de um sistema (totalizado, interativo, processual) de efeitos patológicos ( Rego et al., 2002).

Um gestor da área da saúde relata: a Secretaria Estadual de Saúde, ao longo dos últimos meses, vem desenvolvendo inquérito epidemiológico na região da Ajax, o que envolve vários eventos e a análise do solo é um deles. 37

A terra su perficial foi analisada pela Co $m p a-$ nhia de Tecnologia e Saneamen to Ambiental do Estado de São Paulo (Cetesb), mostrando que há chumbo no solo, mas não em concentrações que (...) exijam a remoção dos moradores de suas casas. 37 O laudo (...) também aponta a existência de chumbo em águas subterrâneas da área em que se localiza a Ájax. 40

De Marchi (2002), ao com entar o aciden te de Seveso, Itália, em que houve liberação de uma nuvem tóxica com dioxina proven i en te de uma indústria química, refere que ninguém na cidade sabia que estava em situação de ri sco, não havendo consciência do problema, tantopor parte da população local, como também por parte das autoridades públicas, incluindo a sanitária. Se em mui tos aspectos os aciden tes pod em ter conseqüências semelhantes (...), as diferenças maiores se encontram na resposta da sociedade a esse tipo de acidente. Essas diferenças revelam a vulnera bilidade das populações em termos da capacidade de resposta no sistema social, que ou protege as pessoas (...), como foi o caso de Seve so, ou abandona as mesmas a sua própria sorte, como foi o caso de Bhopal, Índia.

Neste aspecto, a relação entre saúde e ambi en te será moldada pela intervenção de alguns setores do sistema social, visando reverter o processo de adoecimen to das crianças intox icadas. O seguimento (follow-up) desta população éacompanhado pela imprensa, que em outu bro de 2002 traz com de sta que a inform ação: cai con centração de chumbo entre as crianças do Tangarás. O resultado da terceira amostra de sangue (...) indica que a contaminação caiu porque o bairro não conta mais com o emissor do metal, uma vez que as atividades da fábrica de ba terias fo ram suspensas. 60

\section{O que foi fei to}

Algumas ações de intervenção no âmbito da clínica e da vigilância sanitária e epidemiológica, além de ações emergenciais de descontaminação, são descritas nas matérias categorizadas como o que foi fei to. A ex pressão de expecta tivas da população diante das ações de in- 
Quadro 2

Títulos de matérias jornalísticas sobre a contaminação por chumbo: O que foi descoberto (abril a dezem bro de 2002).

\begin{tabular}{|c|c|c|}
\hline & Jornais/matérias & Data \\
\hline 3 & FSP/Em Bauru, já são 88 crianças intoxicadas & $30 / 04 / 2002$ \\
\hline 4 & JC/ Alta do sagem de chu mbo já ati nge 124 crianças & \\
\hline 6 & OESP/Estado promete divulgar áreas contaminadas & $4 / 05 / 2002$ \\
\hline 7 & JC/Nova coleta de sangue avalia chumbo & $5 / 05 / 2002$ \\
\hline 8 & FSP/Amostras são coletadas em Bauru & $7 / 05 / 2002$ \\
\hline 9 & JC/Cetesb vai mapear chumbo no Zôo & $7 / 05 / 2002$ \\
\hline 12 & JC/Crianças com alta taxa de chu mbo fazem mais exames & $11 / 05 / 2002$ \\
\hline 13 & JC/Chumbo: Cen trinho avalia crianças & $12 / 05 / 2002$ \\
\hline 14 & JC/Cetesb começa hoje a coleta de solo & $14 / 05 / 2002$ \\
\hline 15 & $\mathrm{JC} /$ Laudosobre chumbo sai em 20 dias & $15 / 05 / 2002$ \\
\hline 17 & JC/Já são 162 com alta do sagem de chumbo & $17 / 05 / 2002$ \\
\hline 19 & JC/MT avalia condições de saúde dos funcion á rios da Ajax & $23 / 05 / 2002$ \\
\hline 20 & FSP/Chu m bo afeta 364 crianças em 3 Estado s & $23 / 05 / 2002$ \\
\hline 21 & JC/Contaminados por chumbo já são 186 & $25 / 05 / 2002$ \\
\hline 22 & JC/Polícia inve stiga carcaças de baterias & $28 / 05 / 2002$ \\
\hline 23 & JC/Alta do sagem de chu mbo já ati nge 213 & $1 / 06 / 2002$ \\
\hline 24 & FSP/Fábrica divulga laudo sobre contaminação & $8 / 06 / 2002$ \\
\hline 25 & JC/Caso Ajax está na lista do Greenpeace & $11 / 06 / 2002$ \\
\hline 26 & JC/Resultados das análises do caso Ajax já estão atrasados & $19 / 06 / 2002$ \\
\hline 27 & FSP/Funasa avalia riscoà saúde para morador de área contaminada & $21 / 06 / 2002$ \\
\hline 28 & JC/ Funasa estudará impacto do caso Ajax & $27 / 06 / 2002$ \\
\hline 29 & JC/Seis áreas brasileiras serão alvo do estu do & $27 / 06 / 2002$ \\
\hline 32 & JC/Cetesb en tregará laudos à Saúde na próxima semana & $29 / 06 / 2002$ \\
\hline 34 & JC/ Mais 13 crianças estão com alta con centração de chumbo & $4 / 07 / 2002$ \\
\hline 35 & JC/Cetesb entrega laudos sobre chu mbo à vigilância da DIR & $24 / 07 / 2002$ \\
\hline 36 & JC/DIR faz mistério com laudos do chu m bo & $25 / 07 / 2002$ \\
\hline 37 & JC/Novos laudos do chu mbo já são analisados pela DIR-10 & $3 / 08 / 2002$ \\
\hline 39 & JC/Existem outras fon tes de contaminação, diz Ajax & $10 / 08 / 2002$ \\
\hline 40 & JC/Chu mbo também contamina água & $10 / 08 / 2002$ \\
\hline 42 & JC/Comissão questiona a dem ora para os laudos & $14 / 08 / 2002$ \\
\hline 48 & JC/Empresa clan des tina é descartada pela DIR & $17 / 08 / 2002$ \\
\hline 51 & $\mathrm{JC} /$ Painel mostra defasagem no com ba te ao saturnismo & $28 / 08 / 2002$ \\
\hline 56 & FSP/Morre criançacontaminada por chumbo & $17 / 09 / 2002$ \\
\hline 60 & JC/Cai con centração de chumbo en tre as crianças do Tangarás & $16 / 10 / 2002$ \\
\hline
\end{tabular}

tervenção con fere à imprensa uma espécie particular de "con trole social” ( Quad ro3).

Com relação aos cuidados assistenciais à saúde das crianças expostas, a imprensa relata, em maio de 2002, um movimento de adesão de diversas instituições de ensino/pesquisa e de voluntários às esferas municipal e estadual do s etor saúde.

A iniciativa é do Hospital de Reabilitação de Anomalias Grânio-Faciais-USP (Centrinho) e envolve mais de uma dezena de pa rceiros (...). O superintendente do Centrinho (...) explica que pretende reunir estudantes (...) de cursos como nutrição, psicologia, serviço social, odontologia, biologia, en tre outros. As crianças fo ram selecio- nadas por profissionais (...) da Prefeitu raMunicipal de Bauru e serão examinadas du ra nte todo o sábado por uma equipe multidisciplinar, formada por médicos neu ropediatras, fonoaudiólogos e pediatras. 5

Ações resolutivas de maior complexidade são descritas. Cerca de 20 crianças contaminadas ( com índice acima de 25 microgramas de chu mbo por decilitro de sangue) serão internadas (...) em ci clos de 20 dias, até normalizar o índice. Como o medicamen to pode produzir efei tos colaterais como aumento da pressão arterial e problemas renais e neurológicos, a internação é necessária para aco mpanhar de perto as crianças e intervir se for necessá rio. 30 


\section{Quadro3}

Títulos de matérias jornalísticas sobre a contaminação por chumbo: O que foi fei to (abril a de zem bro de 2002).

\begin{tabular}{lll}
\hline & Jornais/matérias & Data \\
\hline 5 & JC/Centrinho terá voluntários em proj etos & $1 / 05 / 2002$ \\
10 & JC/Empresa assina termo de ajuste de con dut a & $7 / 05 / 2002$ \\
11 & JC/Centrinho con ti nuará atendimen to às crianças com alta do sagem de chu m bo & $8 / 05 / 2002$ \\
18 & JC/CPA da Unesp começa a aten der as crianças & $17 / 05 / 2002$ \\
22 & JC/Polícia inves tiga carcaças de baterias & $28 / 05 / 2002$ \\
30 & FSP/20 crianças contaminadas serão internadas & $29 / 06 / 2002$ \\
31 & JC/Crianças contaminadas por chumbo serão internadas & $29 / 06 / 2002$ \\
33 & JC/Técnicosfederais e estaduais estão em Ba uru para ajudar a DIR no caso Ajax & $2 / 07 / 2002$ \\
38 & JC/Caso Ajax aguarda medidas da DIR-10 & $10 / 08 / 2002$ \\
41 & JC/DIR-10 divulgará medidas sobre chu mbo nesta semana & $13 / 08 / 2002$ \\
44 & JC/Semma interdita córrego V. Limpa & $15 / 08 / 2002$ \\
52 & JC/Ações de de s contaminação serão colocadas em prática & $29 / 08 / 2002$ \\
54 & JC/Descontaminação de caixa d'água começa amanhã & $10 / 09 / 2002$ \\
55 & JC/DAE limpa caixas d'água de área contaminada por chumbo & $12 / 09 / 2002$ \\
58 & JC/Terra com chu mbo não tem fim certo & $14 / 10 / 2002$ \\
61 & JC/Descontaminação ainda é impasse & $26 / 10 / 2002$ \\
62 & JC/Terra será armazen ada na fábrica & $26 / 10 / 2002$ \\
63 & JC/Descontaminação será retom ada dia 4 & $29 / 10 / 2002$ \\
64 & JC/Chumbo: de s contaminação começa hoje & $04 / 11 / 2002$ \\
\hline
\end{tabular}

A inters etorialidade tem espaço nas medidas tom adas em prol da pro teção a esta população. Um termo de ajuste de co $n$ duta foi propo sto pelo Ministério Público do Trabalho e Estadual, (com objetivo de) garantir que não ocorram problemas de contaminação do meio ambiente no futuro. 10

Secretaria Municipal do Meio Ambiente interdita córrego Vargem Limpa. O motivo da medida é a concentração de chumbo detectada no local através de análise de amostras feitas pela Cetesb. 44

A Cetesb fez algumas recomendações referentes a medidas que podem ser adotadas na área contaminada (como) a raspagem do solo, pavimentação das ruas e passeios, limpeza de telhados e pa redes das casas, concret a gem dos quintais ou plantação de grama nos mesmos e verificação das caixas d'água dasresidências. 38

A secretária (municipal de saúde) explica que há uma seqüência de ações a serem colocadas em prática. "Estamos reunindo as Secret a rias de Obras, Meio Ambiente, Administrações Regionais e Departamento de Água e Esgoto para estabelecer a seqüência. Como não é um pro ced $i$ mento só da Saúde temos que ouvir os técn i cos de cada área específica".52

Em novembro de 2002, a imprensa acompanha um acontecimen to inusual na crônica dos suces sivos aci den tes ambi entais que se tornaram públ i cos no Brasil. Tomando um rumo diferen te dos morosos e ineficientes processos que tornam o curso da vida destas populações vulnerá veis mais difícil, o noticiário documenta ações emer genciais - e seus con tra tempos de s envo lvidas neste bairro.

Os trabalhos de raspagem do solo (...) foram interrompidos no meio do dia devido à chuva. Supervisionados por servidores municipais, funcionários da Ajax iniciaram a reti rada de cinco centimetros de solo superficial. 65

Algumas contradições humanas, como o fato de moradores da região contaminada estarem dificultando as ações de descontaminação, foram observadas. Em seis casas, os moradores impediram a entrada dos funcionários, que não puderam executar a aspiração do interior das residências e a raspa gem de terra dos quintais. Um morador refere que só raspar não vai resolver nada. O bom seria pavimentar. É um trabalho inútil. Se o chumbo penetrou no solo, não é só raspar por cima que vai adiantar... A diretora do Departamento de Saúde Coletiva (Secretaria Municipal de Saúde) esclarece que as ações são consideradas prioritárias e têm como objetivo evitar a recontaminação das crianças que apresentam altos indices de chumbo no sangue e estão recebendo acompanhamen to médico. 66 
Desde a conclusão do estudo epidemiológico (...), a administração municipal realizou a limpeza de cerca de 300 caixas d'água (...) e foram reti rados 70 caminhões de terra. O material está sendo depositado em um barracão localizado na Fábrica de Ba terias Ajax e deve ser analisado pela Cetesb. 66

Embora se con tabilizem casos de exposição a agen tes tóxicos, com repercussões importantes sobre a saúde de populações, no Brasil e no mundo, é no âmbi to local que muitas decisões precisam ser tomadas. A escassez de protocolos ou "manuais" para atuar diante de situações emer genciais foi notada. A secretária (municipal de saúde) explica que como o assu n to é novo su rgi ram várias dúvidas. 52 "Ainda temos muitas dúvidas e preferimos discutir melhor. Não podemos correr o risco de contaminar os servidores ( que atuarão na de s contaminação)".54 Também se enfatizou a questão do destino da terra resultante da raspagem do solo: "o que faremos com osresíduos?". 52

Ao realizar previsões e tomar decisões num con tex to de incertezas, de riscos tecnológicos, ambientais e estruturais, Hottois propõe uma ética de solidariedade (...), ba seada (...) no diálogo aberto, que implica o confronto pluralista e interdisciplinar; na é tica reguladora; no pragmatismo; na não-exclusão do sentimen to (...) do co njun to de elemen tos que cooperam na tomada de de cisão ética; na ética da ambivalência, no sentido de ser esta uma escolha, e não uma conclusão lógica, ou um resultado mecânico; na ética evolutiva e da reversibilidade dos princípios; na ética da co-responsabilidade (Hottois, 1994, apud Si lva \& Schramm, 1997).

Diante da magnitude dos fatos e seus desdobram entos, e da premente necessidade de to$m$ adas de decisão, estudos devem ser efetuados.

Funcionários da Funasa (vão) fazer um estudo sobre o impacto ambiental da suspeita de contaminação por chumbo na cidade. O coordenador geral de Vigilância Ambiental em Saúde do Centro Nacional de Epidemiologia da Funasa (...) disse que espera que, a partir dos resultados, possam ser estabelecidas práticas de prevenção e orientação sobre saúde e meio ambiente. 33

Também é recon hecido que as leis de licenciamento ambiental precisam de atualizações constantes, à medida que a industrialização vai sof rendo o impa cto de novas tecnologias e os próprios métodos de aferição da poluição desenvolvem-se ao longo do tempo. ${ }^{2}$ Lewinsohn (1997) refere alguns exemplos de crises que su scit a ra $m$ a consciência ecológica, que, con tu do, não sig- nificam que os problemas ambi entais tenham sido inteiramente compreendidos a seu tempo, nem que as soluções tenham sido suficientes. O que espanta é que civilização após civilização caia em armadilhas semelhantes, experimen te crises parecidas e tente lidar com elas tardiamente e por soluções técnicaspa rcia is (Lewinsohn, 1997).

\section{Considerações finais}

O período histórico coberto pela pres en te análise não con templa a totalidade dos fatos, uma vez que o processo encontra-se em curso e a história vai sen do escrita no acompanhamento co tidiano dos acon tecimentos.

A leitura de matérias selecionadas para a categoria o que aconteceu mostra um papel eminentemente descritivo da imprensa, relatando à sociedade uma sucessão de acon tecimentos, com uma con tex tualização pró pria do meio "jornal".

Ao abordar o que foi de s coberto, o papel da imprensa como tradutor de diagnósti cos médico-dínicos, epidemiológicos e ambi entais mostra uma atuação de mediação entre os diferentes setores da sociedade, ainda que sua abord agem não apreenda a natureza com plexa, subjetiva e con tex tual da relação saúde - dœença-cuid ado.

A expressão de expectativas da população diante das ações de intervenção no âmbito da clínica e da vigilância sanitária e epidemiológica, e suas contradições diante das ações emergenciais de descontaminação, mostradas nas matérias categorizadas como o que foi feito, con fere à imprensa uma espécie particular de con trole social.

Na medida em que interessam ao campo da saúde todos os dispositivos sociais que possam contribuir para melhorar a existência individual e coletiva (Njaine \& Mi n ayo, 2004), a presen te refl exão con s ti tui uma con tri buição à el a boração de programas edu c a tivos que têm como foco os cuidados com o meio ambien te e as suas repercussões sobre a saúde da população. 


\section{Colaboradores}

NE Tomita trabalhou na concepção teórica, análise e redação final do texto; NAMR Padula participou na coordenação do GEPICCB e discussão dos a chados.

GEPICCB - Gru po de Estu do da In toxicação por Chu mbo em Crianças de Bauru-cons ti tui um locus privilegiado de discussões sobre este problema socioambi ental e sanitário e seus participantescon tribuem na forma de reflexão coletiva sobre o tema.

\section{Referências bibliográficas}

Canclini NG 2002. Gidades e cidadãos imaginados pelos meios de comunicação. Opinião Pública 8:40-53.

Centers for Disease Control and Preventi on 2002. Case studies in environmental medicine: lead toxicity. Disponível em <http://www.phppo. cdc.gov/cdc Recom mens/showarticle.asp?a_artid $=$ P0000017\&Top Num $=\ldots . .16$ April 2002

De Ma rchi B 2002. Comunicação e informação de riscos: a experiência da comunidade eu ropéia com os grandes ac i den tes indu striais, pp. 40-56. In MFS Porto \& CM Freitas (orgs). Problemas ambientais e vulnerabilidade: abord a gens integradoras pa ra o campo da saúde pública. CESTEH/ENSP/Fiocruz, Rio de Ja n ei ro..

Ho t tois G 1994. Vérité objective, puissance et système, solidarité. (D'une étique pour l'age technoscientifique). Revue Transdisciplinaires em Santé 1:69-84 apud Si lva e Shcramm.

Instituto Ambiental Vidágua 2002. Nota oficial 08/04/ 2002. Poluição por chumbo em Bauru. Disponível em $<$ http://www.vidagua.org.br/chumbo.htm.>. 16 April 2002

Lefèvre F 1996. O culto da dro ga na mídia: um mês de droga na Folha de S. Paulo de 1994. Universidade de São Paulo, Faculdade de Saúde Pública, Departamento de Prática de Saúde Pública. Série Mon ográfica no 4. Eixo Promoção de saúde. São Paulo.

Lewinsohn TM 1997. Deb a te sobre o artigo de Elmo Rodrigues da Silva \& Fermin Roland Sch ramm. Cadernos de Saúde Pública 13:374-376.

Mi n ayo MCS 1993. O desafio do conhecimento: pesquisa qualitativa em saúde. Hucitec-Abrasco, São Paulo.

Moreira CLB, Zanella CP, Bitencourt MT \& Schut tel S 2002. A saúde no jornal: o caso do Correio do Povo, 2001, pp. 51-61. In JO Silva (org). Saúde na mídia. $\mathrm{D}$ acasa Editora, Porto $\mathrm{Al}$ egre.

Morei ra FR \& Morei ra JC 2004. A cinética do chu m bo no organismo humano e sua importância para a saúde. Ciên cia e Saúde Col etiva 9:167-181.

Njaine K \& Minayo MCS 2002. Análise do discurso da im prensa sobre rebeliões de jovens infra tores em regime de privação de liberd ade. Ciência e Saúde Coletiva 7:283-297.

N jaine K \& Min ayo MCS 2004. A violência na mídia como tema da área da saú de pública: revisão da literatura. Ciên ciae Saúde Col etiva 9:201-211.
GEPICCB: Carlos Hen rique Ferreira Martins, Carice Umbelino de Freitas, Esiquiel de Miranda, José Alberto de Souza Freitas, José Gu alberto Tuga Martins An gerami, José Roberto Pereira Lauris, Kátia de Freitas Alva renga, Márcia Helena Simonetti, Márcia Ma ria Ferreira Lima, Ma ria Hel ena de Abreu, Nil ceEmy Tomita, Niu ra Ap a recida de Mo u ra Ribei ro Padula, Ol ga Ma ria Piacen tin Rolim Rodrigues, Patrícia de Abreu Pinheiro Crenitte, Plínio Ferraz, Telma Ma ria Ribei ro

Paolielo MMB, Guti errez PR, Turini CA, Ma t suo T, Mezzaroba L et al. 1997. Valores de referência para plu mbemia em população urbana. Revista de Saúde Públ ica 31:144-148.

Porto MFS 2002. Entre a saúde e a vulnerabilidade: em busca de uma abordagem ecossocial em problemas de saúde e ambiente, pp. 125-136. In MFS Porto \& CM Freitas (orgs). Probl emas ambientais e vulnerabilidade: abord agens integradoras pa ra o campo da saúde pública. CESTEH/ENSP/Fiocruz, Rio de Janei ro.

Quitério SL, Silva CRS, Vaitsman DS, Martinhon PT, Morei ra MFR et al. 2003. Uso da poeira e do ar como indicadores de contaminação ambiental em áreas circunvizinhas a uma fon te de emissão estacionária de chu m bo. Cadernos de Saúde Pública 17:501-508.

Rego RCF, Barreto ML \& Killinger CL 2002. O que é lixo afinal? Como pensam mulh eres re si den tesna peri feria de um grande cen tro urbano. Cadernos de Saúde Pública 18:1583-1591.

Rojas M, Espinosa C \& Seijas D 2003. Asociación entre plomo e sangre y parámetros sociodemográficos en población infantil. Revista de Saúde Pública 37:503509.

São Paulo (Estado) 2002. Secretaria de Estado do Meio Ambiente. Auto de In fração e Im posição de Penalidade de Interdição Temporária. Processo no 07/ 00524/01 da CETESB - Companhia de Tec nologiade Saneamento Ambiental: penalidade de interdição temporária por infração aos Artigos 2o, 3o, inciso V; 33 e 51 do Regulamento da Lei 997/76, aprovado pelo Dec reto 8.468/76. São Paulo, em 21/01/2002.

Silva ER \& Schramm FR 1997. A questãoecológica: en tre a ciência e a ideologia/utopia de uma época. Cadernos de Saúde Pública 13:355-365.

Tomita NE \& GEPICCB 2003. In toxicação por chu mbo e saúde infantil: ações inters etoriais mudando a histó ria do município de Ba u ru-SP. Ciên ciae Saúde Coletiva, 8:54.

Artigo apresentado em 3/12/2004

Aprovado em 6/06/2005

Versão final apresentada em 18/07/2005 